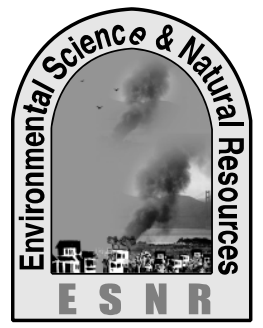

\title{
Criminological Aspects of Meat Misbranding at Dhaka City in Bangladesh
}

\author{
A. Rahman ${ }^{1 *}$, M. A. Haque ${ }^{1}$, A. K. Mia ${ }^{2}$, M. S. Islam ${ }^{1}$ and R. Alam ${ }^{1}$
}

${ }^{1}$ Department of Food Technology and Nutritional Science, ${ }^{2}$ Department of Criminology and Police Science, Mawlana Bhashani Science and Technology University, Bangladesh

"Corresponding author: rahmanftns@gmail.com

\begin{abstract}
The ultimate goal of this study was to investigate the level of meat misbranding and adulteration from slaughterhouses, which is an indirect criminal activity according to the food law. In this study 87 slaughterhouses were selected from 30 markets in Dhaka municipal area purposively to collect data through a well-structured questionnaire. Results showed that a significant percentages of illegal activities done in slaughterhouses. Low weight given during the selling operations, mixing low quality species of meat with high quality one, low quality part of meat through hiding consumer concerns, water mixing before or after slaughter, un-hygienic practices and the level were $56.32 \% ; 49.43 \% ; 42.53 \% ; 72.41 \%$ and $85.18 \%$ respectively. On the other hand, about $8.04 \%$ slaughterhouse used different types of non-meat chemical ingredients illegally to their product. Among four observed chemical sodium phosphate was used in $2.3 \%$ of slaughterhouses, nitrate \& nitrite was used in $1.15 \%$ of slaughterhouses, sodium chloride was also used in $2.3 \%$ of slaughterhouses and cleaners \& sanitizers was used in $3.45 \%$ of slaughterhouses. About $91.96 \%$ of slaughterhouses did not use those non meat ingredients chemical.
\end{abstract}

Key words: Consumer, Fraud, Meat and Slaughterhouse

\section{Introduction}

The food supply system is vulnerable to various types of contamination and adulteration. Consumers may be victim of adulteration of food, poisoning food and food crimes and by indications misleading (Croall, 2009). Three facts must be present simultaneously at any crime: an appropriate target is available, there is the absence of a suitable guardian to protect the crime from occurring and likely an offender is present (Cohen et al., 1979). Naturally occurring meats are composed of water, muscle, connective tissue, fat, and bone. Meat can be adulterated and misbranded through different criminological activities from slaughterhouse in metropolitan areas. Therefore it is necessary to adopt community rules and regulations to the nutrition and health claims on foods. . The consumers preferring to eat fresh meat and scientific studies showed that fresh meat has limited effect on the palatability and eating quality of red meat (Gracey et al., 1999). Issues of consumer safety, compliance with religious rules and detection of fraudulent activities drive to develop new methods of identifying meat adulterations.

Oxford Advanced Learner's Dictionary describes food adulteration as a way of making food or drink impure through the addition of another substance to it. Adulteration of meat involves substitution of high cost or good quality with cheaper, undesirable quality meat (Sharma, 1999). Meat adulteration with inter-species is very common in many parts of the world (Barai et al., 1992; Sharma, 1999; Shears, 2008), and frauds consumers through replacing costly meats with low cost alternatives (Barai et al., 1992). To prevent these practices, article (13) of Slaughterhouse and Meat Inspection Act (SMIA) (1999) estimates with the prevention of fraud and adulteration that nobody shall sale meat claiming one species of meat for other species of meat or nobody shall sale meat by mixing two different species of meat.
Meat also contains moisture retained from post evisceration processing. Meat is injected with water, but some water is absorbed during cooling in a chill-tank. Absorption of water during post-evisceration processing is known as absorbed water. Meat occupational periodically washes red meat carcasses to reduce moisture loss or shrink. Beef carcasses and their parts chilled with water with post-evisceration processing must be appropriately labeled with the statement of retained water otherwise it will be a fraud (USDA).

Due to overcrowding, poverty, inadequate sanitary conditions, and poor general hygiene, food-borne infections are on rise in slaughterhouses. Materials and equipments used in slaughterhouse need to hygienic and sanitize regularly with clean water or detergent solution. Contaminated meat is one of the main sources of foodborne illnesses (Bhandare et al., 2007). Raw meat in open-air local retail markets without proper temperature control purchased by around $23 \%$ households in Karachi (Anjum et al., 2004).

The substitution of low quality part of meat with greater quality is a common practice in many parts of the world. According to article (13.2) of Slaughterhouse and Meat Inspection Act (1999) no substance shall be mixed to alter the obvious quality or taste and also to increase the weight of meat is forbidden. Meat adulteration granted as inevitable and the main cause to this is an excess demand over supply (Shears, 2008).

Chemical ingredients used to improve tenderness, improve and stabilize color, increase safety, or increase water holding capacity in meat. The reason of meat legislation is to provide safety to the consumers related to economy and religion (Barai et al. 1992) and for health (Sharma, 1999). Oxidation is more apparent in red meat or beef than white meat. Meat containing $10 \%$ water and up to $0.5 \%$ sodium phosphate to have either lower Warner-Bratzler shear force values, increased water-holding capacity and more juicy or tender, although cooking influenced this relationship (Jones et 
al., 1989). Addition of chemicals may be harmful for consumers in different ways. Due to the relatively high toxicity of nitrate and nitrite the maximum permit level in meat is $200 \mathrm{ppm}$. There are different types of nitrosamines, most of which are known as carcinogens (Anwar et al., 2000)

The objective of the present study was to investigate the level of meat misbranding and adulteration from slaughterhouses through different ways of criminal activities in Dhaka municipal area.

\section{Materials and Methods}

\section{Place of study}

Study was conducted in Dhaka (Capital city of BD) municipal area to measure the level of meat adulteration and misbranding. From 30 markets 87 slaughterhouses were selected through purposive sampling procedure for this study.

\section{Study design}

The study was a cross-sectional study which focused on the criminological aspects of food misbranding in Bangladesh through meat from slaughterhouses. This study was conducted to build awareness among consumers to protect their right and health.

\section{Sampling technique}

Purposive sampling techniques have been used to this study. Meat adulteration involves with a wide area of public interest. Because of its high commercial value, meat attracted the attention of adulterators for centuries. Meat may be adulterated by sellers in many ways. Common illegal methods practiced in slaughterhouses inject water to increase weight of the product; practice to give lower weight than legal one; mix other low valued species meat with high valued species like buffalo meat with beef; practice to give low quality part of meat through hiding consumers concerns; unhygienic method from slaughter to sell point; use blood or other chemicals to represent to the consumers like a fresh product; improper sanitation or cleaning process into slaughterhouses.

\section{Data collection}

Most of the important material used for the study was a set of interview schedule. For assessing the existing management system a face to face questionnaire interview was carried out among the different representative of slaughterhouses in the study location. In addition, the final conception was drawn after performing a specific personal site visit throughout the study period. For conducting that specific interview and data collection the representative from slaughterhouses were separated on the basis of reconnaissance survey.

\section{Result and Discussion}

\section{Mixing low valued species meat with high valued one} and low weight giving tendency

The number of slaughterhouses who mixed low quality meat with high quality meat (like meat from buffalos with cow's meat) in their business was about $49.43 \%$ and which is almost fifty percentages of all slaughterhouses. Inter species meat adulteration is very common in many region of the world (Shears, 2008). About $50.57 \%$ (Table 1) of slaughterhouses did not involve with that type of fraudulent activity. Table 1 shows the percentage of slaughterhouses practice to give lower weight than the legal weight during selling process. As in the table $156.32 \%$ of slaughterhouses practiced this occurrence in Dhaka municipal area and over $43 \%$ of sellers did not practice to give low weight to their consumers during selling operations.

Table 1. Mixing low valued species meat with high valued one and lower weight giving tendency to meat $(\mathrm{n}=87)$

\begin{tabular}{|l|l|l|}
\hline $\begin{array}{l}\text { Mixing low } \\
\text { valued species }\end{array}$ & Number & Percentage \\
\hline Yes & 43 & 49.43 \\
\hline No & 44 & 50.57 \\
\hline Total & 87 & 100 \\
\hline Lower weight & Number & Percentage \\
\hline Yes & 49 & 56.32 \\
\hline No & 38 & 43.68 \\
\hline Total & 87 & 100 \\
\hline
\end{tabular}

Water mixing tendency in meat during selling periods Among different types of fraudulent activities, water feed before slaughter and water mixed after slaughter to increase weight of meat was significantly important. About $21.84 \%$ (Table 2) of slaughterhouses used less than 10 liter of water for each cattle. About $20.69 \%$ of slaughterhouses used 10 to 20 liter of water for each cow. A significant number $(29.88 \%)$ of sellers used more than 20 liter of water to weight gain of lean meat. This study also found that $27.59 \%$ of slaughterhouse was not involved with addition of water.

Table 2. Amount of water mixing in meat during selling periods $(n=87)$

\begin{tabular}{|l|l|l|}
\hline $\begin{array}{l}\text { Water mix for } \\
\text { each animal }\end{array}$ & Number & Percentages \\
\hline No & 24 & 27.59 \\
\hline$<10$ liter & 19 & 21.84 \\
\hline $10-20$ liter & 18 & 20.69 \\
\hline$>20$ liter & 26 & 29.88 \\
\hline Total & 87 & 100 \\
\hline
\end{tabular}

\section{Hygienic practices}

Hygienic practices before or after slaughter is very important activity to safe consumption of meat and meat products. Clean and safe water must be used to wash meat and handler. According to the result about $85.18 \%$ (Table 3 ) of slaughterhouses did not practice hygienic methods and hygienic equipments like knives, hand gloves, sanitizer etc. But $14.82 \%$ percent of slaughterhouses used hygienic method during their activity. 
Table 3. Hygienic practices $(n=87)$ by the slaughterhouses

\begin{tabular}{|l|l|l|}
\hline $\begin{array}{l}\text { Practice hygiene } \\
\text { method }\end{array}$ & Number & Percentage \\
\hline Yes & 16 & 14.82 \\
\hline No & 71 & 85.18 \\
\hline Total & 87 & 100 \\
\hline
\end{tabular}

Low quality meat adding tendency in selling process

Another type of fraudulent activity with meat from slaughterhouses is undeclared part of meat into the consumer bag. Through hiding process from customers a large number of slaughterhouses practice to give low quality meat and it was about $42.53 \%$ (Table 4).

Table 4. Low quality meat adding tendency in selling process $(n=87)$.

\begin{tabular}{|l|l|l|}
\hline $\begin{array}{l}\text { Add low } \\
\text { quality meat }\end{array}$ & Number & Percentage \\
\hline Yes & 37 & 42.53 \\
\hline No & 50 & 57.47 \\
\hline Total & 87 & 100 \\
\hline
\end{tabular}

\section{Chemical adulterants used in Meat}

The fig. 1 represents an overall percentage about chemicals added in meat. There are many chemicals used in meat (beef) among them sodium phosphate; sodium chloride; nitrate and nitrite and cleaner \& sanitizer were observed in this study. According to the result only about $8.04 \%$ (Fig. 1) of slaughterhouses used these types of chemical additives and involved with that type of criminal activity. Most of them $91.96 \%$ of slaughterhouses did not use this type of chemicals in their slaughterhouses.

\section{Chemical adulterants used in meat}

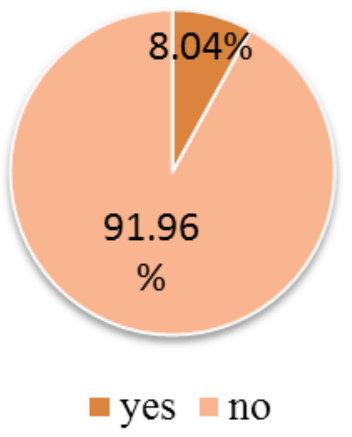

Fig. 1. Chemical adulterants used in meat $(n=87)$

\section{Percentages of each chemical used in meat}

The figure 2 shows the percentage of each chemical used in meat from different slaughterhouses. Cleaner and sanitizer showed the use in slaughterhouses of about $3.45 \%$, which is needed to clean and sanitize equipments and places. Nitrate \& nitrite were used minimum level at about $1.15 \%$. Maximum permit level of nitrate and nitrite in meat is $200 \mathrm{ppm}$ because of its high level of toxicity (Anwar et al., 2000). Where sodium phosphate and sodium chloride both were used as same level at about $2.3 \%$ of slaughterhouses

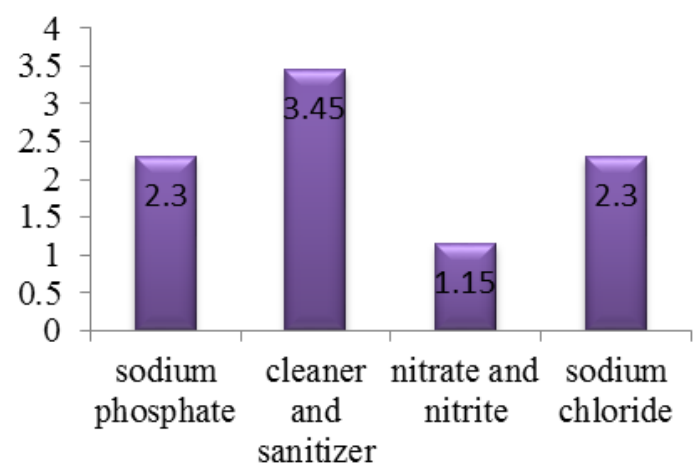

Fig. 2. Chemical used in meat in the slaughterhouses

\section{Conclusions}

Meat adulteration risk found in this study including food defense incidents, unauthorized chemicals, intended to harm or commit food fraud motivated by economic gain is growing in scope, scale, and threat. The adulteration and misbranding risks are direct, indirect, and technical. Consumers also could be the victims of lack of information, misleading and frauds, which in the same time means possibilities of violating their basic rights. Findings of this article show the possibilities of unfair practices, frauds at slaughterhouses and public health vulnerability in each case is because of low good manufacturing practices. More research at operational level should be conducted to take an implementable food safety measure at slaughterhouses.

\section{References}

Anjum, Q.; Omair, A.; Ahmed, Y.; Shaikh, S.; Usman, J. and Qureshi, F. 2004 Frequency of Food Items among Households in a Low Socioeconomic Area of Karachi. J. Pak. Med. Assoc., 54: 580-582.

Anwar, N. 2000. The effect of potassium lactate and sodium diacetate on the microbial, sensory, color and chemical characteristics of vacuum-packaged beef top loin steaks. Master's thesis, Texas A\&M University. Available electronically from http : / /hdl .handle .net /1969 .1 /ETDTAMU -2000 -THESIS -A59.

Barai, B. K.; Nayak, R. R.; Singhal, R. S. and Kulkarni, P. R. 1992. Approaches to the Detection of Meat Adulteration. Trends in Food Science \& Technology, 31: 69-72.

Bhandare, S. G.; Sherikarv, A. T.; Paturkar, A. M.; Waskar, V. S. and Zende, R. J. 2007. A comparison of microbial contamination on sheep/goat carcasses in a modern Indian abattoir and traditional meat shops. Food Control, 18: 854-868.

Cohen, L. E. and Felson, M. 1979. "Social Change and Crime Rate Trends: A Routine Activity 
Approach." American Sociological Review 44: 588- 608

Croall, H. 2009. 'White Collar Crime, Consumers and Victimization' Crime. Law and Social Change 51:127-146.

Gracey, J.; Collins, D. S. and Huey, R. 1999. Meat Hygiene. 10th ed. London: Harcourt Brace and Company Limited; 768 p.

Jones. R. C.; Dransfield, E.; Crosland, A. R and Frareonbe, M. A. 1989. Sensory Characteristics of British Sausages: Relationships with composition and mechanical properties. Journal of the Science of Food and Agriculture, 48: 63-85.

Sharma, B. D. 1999. Meat and Meat Products Technology (Including Poultry Products Technology).

Shears, P. 2008. Food Fraud - A Current Issue but an Old Problem. Plymouth Law Review. (1):118-139 Slaughterhouse and Meat Inspection Act 1999. United States Department of Agriculture (USDA).

WHO. 2005. Preventing Chronic Diseases: A Vital Investment;http://www.who.int/chp/chronic_disea se_report/en/. Accessed 2/14/11. 